American Journal of Pharmacology and Toxicology 4 (4): 130-135, 2009

ISSN 1557-4962

(C) 2009 Science Publications

\title{
Reproductive Toxicology of Tartrazine (FD and C Yellow No. 5) in Swiss Albino Mice
}

\author{
${ }^{1}$ N. Mehedi, ${ }^{1}$ S. Ainad-Tabet, ${ }^{1}$ N. Mokrane, ${ }^{1}$ S. Addou, ${ }^{2}$ C. Zaoui, \\ ${ }^{1}$ O. Kheroua and ${ }^{1}$ D. Saidi \\ ${ }^{1}$ Laboratory of Physiology of Nutrition and Food Safety, \\ University of Oran, Oran, Algeria \\ ${ }^{2}$ Laboratory of Developmental Biology, Department of Biology, \\ University of Oran, Oran, Algeria
}

\begin{abstract}
Problem statement: Tartrazine (FD and C Yellow No. 5) is an orange-colored widely used in food products, drugs and cosmetics. This color has a potential toxicological risk. The current study evaluated the effect of sub-chronic consumption of tartrazine on the male reproductive system. Approach: Tartrazine was administered to adult male mice in drinking water at doses of 0, 0.1, 1 and $2.5 \%$ for 13 weeks. After that period, the weights of testes, epididymides and seminal vesicles were determined. Sperm counts in the testis and epididymides, motility, morphology and testis histology were assessed. Results: Body weight gain, absolute and relative testis, epididymis and seminal vesicles weights did not change. However, sperm count was decreased and sperm abnormalities were increased in the $2.5 \%$ tartrazine treated groups compared to the control. Sperm motility and histological changes in testis were observed in the middle and high treated groups. Conclusion/Recommendations: We concluded that excessive tartrazine consumption can have adverse effects on the male reproductive function. We suggested conducting surveys among the population to estimate their daily intake.
\end{abstract}

Key words: Subchronic toxicity, tartrazine, sperm counts, motility, morphology, mouse

\section{INTRODUCTION}

Synthetic organic dyes were developed to provide a more economical and extensive array of colorants. By the early 1990's, natural and synthetic color additives were used extensively to color foods, drugs and cosmetics. Color is an important characteristic and selection criterion for food choice. Studies have highlighted this importance and have shown how selection may change among certain populations and over time ${ }^{[1]}$.

Tartrazine (FD and C Yellow No. 5) is a monoazo pyrazolone dye, used mainly to color several foods such as soft drinks, juices, biscuits, ice creams, sauces, mustard, snacks, decoration and coatings, flavored processed cheese, drugs and cosmetics (shampoos, colognes, toothpastes, soaps). In addition, this food colorant is many used in cooking in developing countries as a substitute for saffron. The Acceptable Daily Intake (ADI) for humans is $0-7.5 \mathrm{mg} \mathrm{kg}^{-1}$ body weight $^{[2]}$.

Tartrazine has been implicated as the food additive most often responsible for allergic reactions; chiefly affecting atopic individuals ${ }^{[3-7]}$. A number of data describing tartrazine-related hyperactivity in children ${ }^{[8]}$ and induced DNA damage in the colon of mice at doses close to the $\mathrm{ADI}^{[9]}$. Prolonged use of this dye increases the number of gastric mucosa lymphocytes and eosinophils of Wistar rats ${ }^{[10]}$.

Previous reports on the teratogenicity/ reproduction toxicity of tartrazine suggested that there are no treatment-related effects on fertility, gestation, parturition and lactation at 5\% in the diet in rats and mice $^{[11,12]}$. Also, Collins et al. ${ }^{[13]}$ found that tartrazine produced nor toxic and teratogenic effect in rats fed by gavage (60-1000 mg kg $\left.{ }^{-1} \mathrm{day}^{-1}\right)$ and Collins et al. ${ }^{[14]}$ reported the same effects in drinking water $(0.05-0.7 \%)$ in rats. Study on reproductive and neurobehavioral toxicity of tartrazine in mice showed that at the dose of $0.45 \%$ of tartrazine in the diet produced a few adverse effects in neurobehavioral parameters during the lactation period ${ }^{[15]}$. These multigenerational studies may not be sensitive in humans. In fact, rats and rabbits remain fertile after a reduction in sperm counts of more than $90 \%$.

Corresponding Author: Djamel Saidi, Laboratory of Physiology of Nutrition and Food Safety, University of Oran, Oran, Algeria Fax: 21341513025 Tel: 213550231610 
Nevertheless, so far there are no studies on the effect of tartrazine on the testicular toxicity or on the function of the male reproductive system. Mangelsdorf et al. ${ }^{[16]}$ indicated that histopathology and reproductive organs weights analyses provide the best means for detecting substances that potentially affect male fertility and that sperm analysis reflects the results obtained by histopathology and measurement of organ weights.

Therefore, the present report, it is to show that tartrazine affects the functions of the male reproductive system.

\section{MATERIALS AND METHODS}

Chemicals: Tartrazine (C.I. 19140, CAS No 1934-210 , Mw 534.37, synonyms: E 102, Food yellow 4, FD and $\mathrm{C}$ yellow No.5) is an azo dye with the chemical formula 4 5-Dihydro-5-oxo-1-(4-sulfophenyl)-4-((4sulfophenyl) azo)-1H-pyrazole-3-carboxylic acid, trisodium salt was obtained from Courtex International, France. Purity of at $86.7 \%$ was guaranteed by the manufacturer. TritonX-100 was purchased from Sigma, USA, hematoxylin and eosin stains were purchased from Merck, Germany.

Animals and treatments: The studies were conducted on male Swiss albino mice, 4 weeks old and weighing $(20 \pm 2.01)$ g. They were kept under conditions of ambient room temperature and relative humidity. Tartrazine was diluted in water. Mice were divided into four groups of then animals each. The first group was given drinking water as a control, the second the drinking water containing $0.1 \%$ tartrazine, the third the drinking water containing $1 \%$ tartrazine and the fourth the drinking water containing $2.5 \%$ tartrazine each for 13 weeks. Standard food pellets diet and water were given ad libitum for the duration of the experiment. Food and water were measured every day and body weight weekly.

Reproductive performance study: For the study of fertility and general reproductive performance, groups of tartrazine-treated mice, six males per dose group, were mated 1:1 with untreated females for 1 week. Females were then separated and allowed to gestate to term. For females that failed to deliver a litter, this was considered as a sign of male infertility whereas litter delivery indicated male fertility. Litter size and weight after 7, 14 and 28 days of growth were examined.

Evaluation of sperm motility and morphology: After mating, male mice were killed by cervical dislocation. Testes, epididymides were weighed immediately. The left epididymis was excised and placed in a Petri dish containing saline solution (Nacl $0.9 \%)$. The tail region tissue was minced with scalpels for approximately $1 \mathrm{~min}$ and placed in a $37^{\circ} \mathrm{C}$ incubator for $15 \mathrm{~min}$, prior to determining sperm motility. The suspension was stirred; one drop was placed in a hemocytometer. At least 10 microscopic fields were observed at 400x magnification using a standard optical microscope and the percentage of motile sperm was determined ${ }^{[17]}$.

The sperm morphology was assessed by smearing the sperm suspension (in $20 \mu \mathrm{L}$ saline solution) onto a glass slide. Once air-dried, the cells were fixed in $96 \%$ ethanol for $5 \mathrm{~min}$, stained with $0.5 \%$ gentian violet and rinsed with distilled water. A minimum of 600 spermatozoa were examined from each sample under a light microscope $\mathrm{e}^{[17]}$.

Assessment of sperm production: The right epididymis and the right testis were frozen immediately at $-80^{\circ} \mathrm{C}$ after weighing until evaluation. After thawing at room temperature, the head epididymis and the testis were homogenized in 5 or $10 \mathrm{~mL}$ of a solution of $0.9 \% \mathrm{NaCl}$ containing $0.05 \mathrm{~mL}$ Triton $\mathrm{X}-100$. The testis and epididymis homogenates were diluted with $1.5 \mathrm{~mL}$ of the same solution and spermatozoa and spermatids were counted at 400x in a hemocytometer. Five counts per sample were averaged ${ }^{[18]}$.

Histologic examination: Histologic examination of testis was performed. The left testis was fixed in formalin-buffer. Six microns thick paraffin sections were stained with hematoxylin and eosin and examined by light microscopy.

Statistical analysis: The data is expressed as mean \pm SE. Statistical test one way ANOVA was applied to find significant difference between values of various parameters recorded for control and treated animals. $\mathrm{p}<0.05$ was considered statistically significant.

\section{RESULTS}

Food and liquid consumption: Food consumption values were significantly decreased at all experimental groups compared to control. However, liquid consumption was increased at all experimental groups (data not shown). The average $( \pm \mathrm{SE})$ tartrazine intake calculated from liquid consumption, in $\mathrm{mg} \mathrm{kg}^{-1}$ day $^{-1}$, was $(173.9 \pm 0.25),(1767.8 \pm 0.32),(5541.4 \pm 0.47)$ for $0.1,1$ and $2.5 \%$ tartrazine groups, respectively. 
Body and reproductive organ weights in male adult mice: Body weight gain was significantly increased in $1 \%$ tartrazine $(\mathrm{p}<0.05)$ (Table 1$)$. This increased body weight gain is not evidence related dose. A decrease of relative testis and seminal vesicles weight were observed in all treated groups compared to control but not statistically significant. However, their absolute weight did not change (Table 2).

Reproductive performance: The reproductive performance of male mice treated with tartrazine is shown on Table 3. Male mating index was decreased in the $2.5 \%$ treated groups compared to the control values. Weight and litter sizes were, however, decreased in comparison to litters sired from control males. Monitoring of body weight provides an index of general health status of the animals and such information may also be important for the interpretation of reproductive health.

Sperm parameters: Sperm parameters are shown in Table 4. Total number of spermatids count was reduced significantly in the mice administered $2.5 \%$ tartrazine $\quad(\mathrm{p}<0.01)$. Sperm concentration in epididymides was reduced in all treated groups but sperm epididymis reserves were reduced significantly only in mice treated with $2.5 \%$ tartrazine $(\mathrm{p}<0.01)$. The percentage motility was reduced in 1 and $2.5 \%$ treated groups $(\mathrm{p}<0.01)$.

Table 1: Effects of oral ingestion of tartrazine on body weight in adult male mice

\begin{tabular}{lllll}
\hline Concentration $(\%)$ & 0 & 0.1 & 1 & 2.5 \\
\hline $\begin{array}{l}\text { Starting body } \\
\text { weights }(\mathrm{g})\end{array}$ & $19.37 \pm 0.77$ & $18.82 \pm 0.99$ & $20.13 \pm 1.00$ & $21.29 \pm 1.21$ \\
$\begin{array}{l}\text { Final body } \\
\text { weights }(\mathrm{g})\end{array}$ & $37.91 \pm 1.73$ & $35.30 \pm 0.69$ & $42.70 \pm 1.04$ & $38.62 \pm 0.59$ \\
$\begin{array}{l}\text { Body weight } \\
\text { gain }(\mathrm{g})\end{array}$ & $18.54 \pm 2.05$ & $17.05 \pm 0.94$ & $24.16 \pm 1.27 *$ & $17.04 \pm 0.67$ \\
\hline
\end{tabular}

Values are represent mean \pm SE of then mice $(n=10) ; *$ : Significantly different from control value $(\mathrm{p}<0.05)$

Table 2: Effects of oral ingestion of tartrazine on reproductive organs weight in adult male mice

\begin{tabular}{llll}
\hline Concentration (\%) & Testes & Epididymides & Seminal vesicles \\
\hline Absolute weight (g) & & & \\
0.00 & $0.20 \pm 0.01$ & $0.09 \pm 0.01$ & $0.33 \pm 0.03$ \\
0.01 & $0.22 \pm 0.01$ & $0.11 \pm 0.02$ & $0.31 \pm 0.03$ \\
1.00 & $0.21 \pm 0.01$ & $0.09 \pm 0.01$ & $0.33 \pm 0.04$ \\
2.50 & $0.22 \pm 0.01$ & $0.09 \pm 0.01$ & $0.34 \pm 0.03$ \\
Relative weight (\% bw) & & \\
0.00 & $0.59 \pm 0.04$ & $0.26 \pm 0.05$ & $0.92 \pm 0.05$ \\
0.01 & $0.57 \pm 0.04$ & $0.28 \pm 0.04$ & $0.81 \pm 0.08$ \\
1.00 & $0.55 \pm 0.03$ & $0.24 \pm 0.02$ & $0.83 \pm 0.09$ \\
2.50 & $0.55 \pm 0.02$ & $0.24 \pm 0.03$ & $0.85 \pm 0.08$ \\
\hline
\end{tabular}

Values are represent mean \pm SE of six mice $(n=6)$
Morphological abnormalities involved the sperm head (amorphous, macro-or microcephaly) and the sperm flagellum (entangled, twisted, coiled, with ANSA). The percentage morphologically normal spermatozoa were significantly affected in $2.5 \%$ dose level of tartrazine $(\mathrm{p}<0.01)$.

Histology of the testis: Histological examination revealed that semniferous tubules were not identical with conjunctive tissue dystrophy in animals testes treated with $0.1 \%$ tartrazine. Intercellular connections were reduced and imperfect and dilation in some semniferous tubules of testis mice treated $1 \%$ tartrazine. Significant damage was observed in testis mice treated with $2.5 \%$ tartrazine; extensive disruption in semniferous tubules, widening of the interstitial spaces and loss leydig cells. Spermatogenic cells are affected and then depleted with absence of spermatozoa in the lumen (Fig. 1).

Table 3: Fertility and reproductive parameters after 7, 14 and 28 days in offspring

\begin{tabular}{llllc}
\hline Parameters & Control & $0.10(\%)$ & $1.00(\%)$ & $2.50(\%)$ \\
\hline Mating index ${ }^{\varphi}$ & $6 / 6(100)$ & $5 / 6(83)$ & $6 / 6(100)$ & $4 / 6(67)^{* *}$ \\
Average & $8.16 \pm 0.70$ & $7.25 \pm 2.09$ & $5.50 \pm 1.26$ & $6.16 \pm 2.02$ \\
litter number & & & & \\
No. of offspring & 49 & 34 & 30.0 & \multicolumn{2}{l}{37} \\
Weight $(\mathbf{g})^{\#}$ & & & & \\
7 days & $4.06 \pm 0.10$ & $3.63 \pm 0.1^{*}$ & $4.67 \pm 0.12^{* *}$ & $3.80 \pm 0.09$ \\
14 days & $7.02 \pm 0.09$ & $5.89 \pm 0.18^{* *}$ & $7.25 \pm 0.26$ & $6.00 \pm 0.28^{* *}$ \\
28 days & $16.37 \pm 0.47$ & $13.64 \pm 0.46^{* *}$ & $13.86 \pm 0.88^{*}$ & $14.96 \pm 0.64$ \\
Litter size $(\mathbf{c m})^{\#}$ & & & & \\
7 days & $6.86 \pm 0.13$ & $6.76 \pm 0.09$ & $7.62 \pm 0.09^{* *}$ & $7.37 \pm 0.10^{* *}$ \\
14 days & $10.36 \pm 0.11$ & $8.97 \pm 0.15^{* *}$ & $9.24 \pm 0.25^{* *}$ & $10.42 \pm 0.22$ \\
28 day & $15.50 \pm 0.14$ & $15.35 \pm 1.17$ & $14.14 \pm 0.34^{* *}$ & $14.23 \pm 0.41^{* *}$ \\
\hline
\end{tabular}

${ }^{\varphi}$ : No. of males producing a pregnant female/No. of males cohoused with females; Values are represent mean \pm SE of six mice $(n=6)$; \#: Statistic effectuated on 30 offspring for weight and litter size, $\mathrm{n}=30$; *: Significantly different from control value $(\mathrm{p}<0.05)$; **: Significantly different from control value $(\mathrm{p}<0.01)$

Table 4: Sperm parameters in male mice treated with tartrazine

\begin{tabular}{|c|c|c|c|c|}
\hline & Control & $0.10(\%)$ & $1(\%)$ & $2.5(\%)$ \\
\hline \multicolumn{5}{|l|}{ Spermatozoa count } \\
\hline $\begin{array}{l}\text { Per epididymis } \\
\left(\times 10^{6}\right)\end{array}$ & $2.88 \pm 0.37$ & $2.40 \pm 0.65$ & $2.00 \pm 0.10$ & $0.60 \pm 0.09 * *$ \\
\hline $\begin{array}{l}\text { Per g epididymis } \\
\left(\times 10^{6}\right)\end{array}$ & $48.92 \pm 5.01$ & $26.41 \pm 3.20 * *$ & $28.76 \pm 2.64^{*}$ & $11.87 \pm 3.35^{* *}$ \\
\hline \multicolumn{5}{|l|}{ Spermatid count } \\
\hline Per testis $\left(\mathrm{x} 10^{6}\right)$ & $3.96 \pm 0.10$ & $3.91 \pm 0.38$ & $3.96 \pm 0.48$ & $1.40 \pm 0.10^{* *}$ \\
\hline Per g testis $\left(\mathrm{x} 10^{6}\right)$ & $15.92 \pm 1.16$ & $8.52 \pm 1.04$ & $8.45 \pm 1.08$ & $7.22 \pm 0.10^{*}$ \\
\hline Motile sperm (\%) & $83.33 \pm 6.62$ & $84.83 \pm 1.76$ & $56.00 \pm 5.54 * *$ & $56.50 \pm 4.86^{* *}$ \\
\hline Abnormal forms (\%) & $14.67 \pm 0.99$ & $12.25 \pm 0.70$ & $15.17 \pm 3.09$ & $28.00 \pm 1.57 * *$ \\
\hline
\end{tabular}




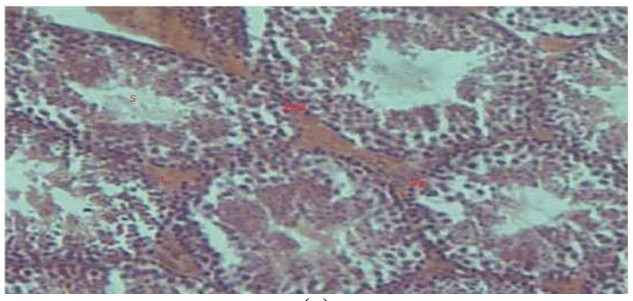

(a)

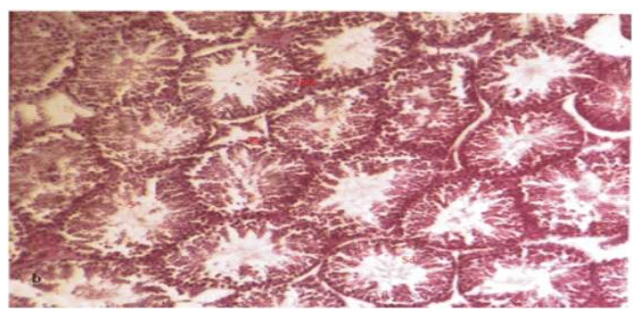

(b)

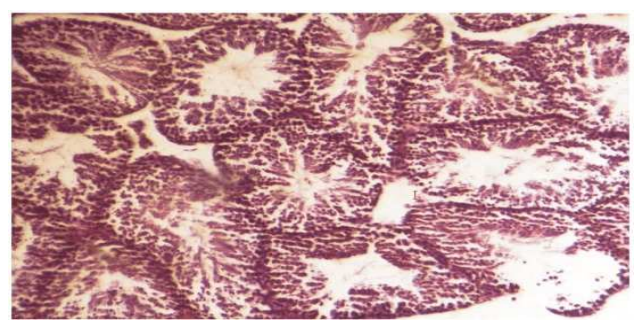

(c)

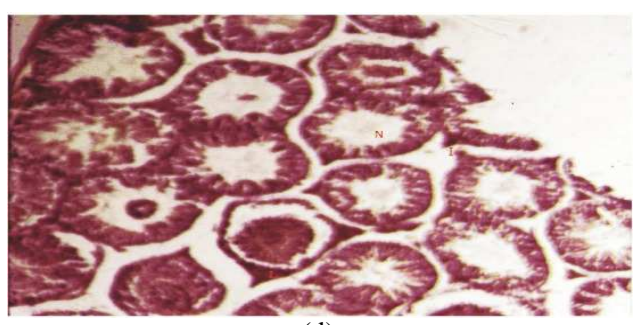

(d)

Fig. 1: (a) Testis from control mouse showing circumscribed semniferous tubules with intact Basement Membranes (BM). Note the Spermatogonia ( $\mathrm{Sg}$ ), Spermatids (Sd), Sperm (S) and interstitial cells of Leydig (L). (b) testis from mouse treated with $0.1 \%$ tartrazine showing the different stages of spermatogenesis and spermatogenesis with lumen containing sperm (S). Note the interstitial cells of Leydig (L) and interstitial space (I), (c) note a wide of interstitial space and dilation of some semniferous tubules. (d) testis from mouse treated with $2.5 \%$ tartrazine showing widening of the interstitial spaces (I) and lumina of the semniferous tubules $(\mathrm{N})$, loss Leydig cells (L). A magnification $\times 250, b, c$ and d magnification $\mathrm{x} 100$

\section{DISCUSSION}

In the present study administration of tartrazine in drinking water decreased the number of testis and epididymal spermatozoa motility and induced abnormalities sperm and damage in testis structure. Increase body weight gain in $1 \%$ tartrazine treated group seemed non dose-related.

The testicular sperm counts and daily sperm production are important indicators for investigators to detect the adverse effects of various factors on spermatogenesis ${ }^{[19]}$. Our results suggest that tartrazine at the dose of $2.5 \%$ in drinking water significantly reduces epididymal and testicular sperm counts including morphological abnormalities. However, the motility was both decreased in 1 and $2.5 \%$ treated groups. These findings were similar to data from AbdelAziz et $a l .{ }^{[20]}$ showed that after 5 daily p.o administration of erythrosin FD and C Red No. 3) at dose of 680 and $1360 \mathrm{mg} \mathrm{kg}^{-1}$ affect the count and motility of epididymal sperm and increased the incidence of sperms with abnormal head. These show that synthetic food colorants may affect the reproductive function.

Even though in the multigenerational reproductive toxicity studies, the tartrazine seems not to affect the reproductive system since the animals were still fertile ${ }^{[11-14]}$, this present study shows that there is decrease in mating index in $2.5 \%$ treated groups. The weight offspring from all treated groups was decreased and their size was reduced only in 1 and $2.5 \%$ treated groups during the lactation period. It therefore seems that the differences caused by tartrazine treatment. However, Tanaka et al. ${ }^{[21]}$ showed the average body weight of male and female offspring was increased significantly in the low-dosed group $(0.15 \%$ of tartrazine) throughout the lactation period. This study attributed that the differences of offspring weight between the control and low-dosed groups were caused not by tartrazine treatment but by the body size at birth.

The histological changes are severely affected in the testis of $2.5 \%$ treated groups. We noted a widening of the lumen of the semniferous tubules due to spermiogenesis stopping and lack of spermatozoa. Also a widening of the interstitial spaces and loss leydig cells were shown. Our results showed that the intercellular connections were reduced and imperfect as well as degeneration in some semniferous tubules of testis mice treated $1 \%$ tartrazine. The dose-levels of tartrazine in the present study produced adverse effect on testis structure. Studies on evaluating effects of chemicals on male fertility indicated that testis histopathology is the most sensitive parameter for detecting any effect ${ }^{[16,22]}$. 
The present study shows that tartrazine has toxic effects on the testis and the epididymides of Swiss Albino mice when it is administered at high doses equivalent to $5541.4 \mathrm{mg} \mathrm{kg}^{-1} \mathrm{day}^{-1}$ and it also affects testis structure and sperm motility at middle doses equivalent to $1767.8 \mathrm{mg} \mathrm{kg}^{-1} \mathrm{day}^{-1}$. These doses level were in excess of the ADI of tartrazine $\left(0-7.5 \mathrm{mg} \mathrm{kg}^{-1}\right.$ body weight). Really, we don't know our daily intake of tartrazine in food but we know that foodstuffs contain $90 \%$ artificial food additives and that tartrazine is present in most foodstuffs especially in drinks and juices $^{[23]}$.

However, it is necessary in developing countries to conduct their own exposure assessment using domestic data. This is because the level of chemicals in food and also the food consumption pattern are different from country to country. Therefore, in conducting risk characterization in developing countries, it is generally recommended to compare the local exposure data with the safe intake level developed by international expert groups $^{[24]}$.

\section{CONCLUSION}

In conclusion, the present data demonstrate that sub-chronic ingestion of tartrazine in drinking water can produce adverse effects on fertility, reproductive performance and sperm parameters in male mice at 1 and $2.5 \%$ of tartrazine. Above the ADI, tartrazine possess adverse effects, it is necessary to carry out surveys among the population for estimate their daily intake of additives.

\section{ACKNOWLEDGMENT}

This research was supported by the Ministry of Higher Education and Scientific Research (MESRS, Algeria). Ms. SACI Malika is gratefully acknowledged for her corrections of the manuscript.

\section{REFERENCES}

1. Clydesdale, F.M., 1993. Color as a factor in food choice. Crit. Rev. Food Sci. Nutr., 33: 83-101. www.ncbi.nlm.nih.gov/pubmed/8424857

2. Joint FAO/WHO Expert Committee on Food Additives (JECFA), 1965. Specifications for the identity and purity of food additives and their toxicological evaluation: Food colors and some antimicrobials and antioxidants. http://www.annals.org/cgi/content/abstract/73/3/51 $1-\mathrm{a}$
3. Bhatia, M.S., 2000. Allergy to tartrazine in psychotropic drugs. J. Clin. Psychiatry, 61: 473-476. http://www.ncbi.nlm.nih.gov/pubmed/10937604

4. Ardern, K.D. and F.S. Ram, 2001. Tartrazine exclusion for allergic asthma. Cochrane Database Syst. Rev., 4: CD000460. http://www.ncbi.nlm.nih.gov/pubmed/11687081

5. Bourrier, T., 2006. Intolerance and allergy to colorants and additives. Revue Française D'allergologie et D'immunologie Clinique, 46: 68-79. DOI: 10.1016/j.allerg.2005.12.002

6. Inomata, N., H. Osuna, H. Fujita, T. Ogawa and Z. Ikezawa, 2006. Multiple chemical sensitivities following intolerance to azo dye in sweets in a 5year-old girl. Allergol. Int., 55: 203-205. http://www.ncbi.nlm.nih.gov/pubmed/17075259

7. Hannuksela, M. and T. Haahtela, 2009. Food additive hypersensitivity--near myth. Duodecim; Lääketieteellinen Aikakauskirja, 125: 527-532. http://www.ncbi.nlm.nih.gov/pubmed/19385342

8. Rowe, K.S. and K.J. Rowe, 1994. Synthetic food coloring and behavior: Adose response effect in a double-blind, placebo-controlled, repeated measures study. J. Pediatr., 125: 691-698. http://www.ncbi.nlm.nih.gov/pubmed/7965420

9. Sasaki, Y.F., S. Kawaguchi, A. Kamaya, M. Ohshita and K. Kabasawa et al., 2002. The comet assay with 8 mouse organs: Results with 39 currently used food additives. Mutat. Res., 519: 103-119. http://www.ncbi.nlm.nih.gov/pubmed/12160896

10. Moutinho, I.L.D., L.C. Bertges and R.V.C. Assis, 2007. Prolonged use of the food dye tartrazine (FD and $\mathrm{C}$ yellow $\mathrm{n}^{\circ}$ ) and its effects on the gastric mucosa of Wistar rats. Braz. J. Biol., 67: 141-145. DOI: 10.1590/S1519-69842007000100019

11. Borzelleca, J.F. and J.B. Hallagan, 1988. Chronic toxicity/carcinogenicity studies of FD and C Yellow No. 5 (tartrazine) in rats. Food Chem. Toxicol., 26: 179-187. http://www.ncbi.nlm.nih.gov/pubmed/3366418

12. Borzelleca, J.F. and J.B. Hallagan, 1988. A chronic toxicity/carcinogenicity study of FD and C Yellow No. 5 (tartrazine) in mice. Food Chem. Toxicol., 26: 189-194.

http://www.ncbi.nlm.nih.gov/pubmed/3366419

13. Collins, T.F.X., T.N.O. Black, L.H. Brown and P. Bulhack, 1990. Study of the teratogenic potential of FD and C Yellow No. 5 when given by gavage to rats. Food Chem. Toxicol., 28: 821-827. http://www.ncbi.nlm.nih.gov/pubmed/2276704

14. Collins, T.F.X., T.N.O. Black, M.W. Donnell and P. Bulhack, 1992. Study of the teratogenic potential of FD and C Yellow No. 5 when given in drinking water. Food Chem. Toxicol., 30: 263-268. http://www.ncbi.nlm.nih.gov/pubmed/1628860 
15. Tanaka, T., 2006. Reproductive and neurobehavioural toxicity study of tartrazine administered to mice in the diet. Food Chem. Toxicol., 44: 179-187. DOI: 10.1016/j.fct. 2005.06.011

16. Mangelsdorf, I., J. Buschmann and B. Orthen, 2003. Some aspects relating to evaluation of the effects of chemicals on male fertility. Regul. Toxicol. Pharmacol., 37: 356-369. DOI: 10.1016/S0273-2300(03)00026-6

17. Yang, J.Y., G.X. Wang, J.L. Liu, J.J. Fan and S. Cui, 2007. Toxic effects of zearalenone and its derivatives $\alpha$-zearalenol on male reproductive system in mice. Reprod. Toxicol., DOI: 10.1016/j.reprotox.2007.05.009

18. Farag, A.T., A.F. El-Aswad and N.A. Shaaban, 2007. Assessment of reproductive toxicity of orally administered technical dimethoate in male mice. Reprod. Toxicol., 23: 232-238. DOI: 10.1016/j.reprotox.2006.12.003

19. Ban, Y., K.M. Komatsu, S. Inagaki and M.H. Nakatsuka, 1995. Testicular spermatid and epididymal sperm head counts as an indicator for reproductive toxicity in rats. Exp. Anim., 44: 315-22. DOI: 10.1538/expanim.44.315
20. Abdel Aziz, A.H., S.A. Shouman, A.S. Attia and S.F. Saad, 1997. A study on the reproductive toxicity of erythrosine in male mice. Pharmacol. Res., 35: 457-62. http://www.ncbi.nlm.nih.gov/pubmed/9299211

21. Tanaka, T., O.Takahashi, S. Oishi and A. Ogata, 2008. Effects of tartrazine on exploratory behavior in a three-generation toxicity study in mice. Reprod. Toxicol., 26: 156-163. DOI: 10.1016/j.reprotox.2008.07.001

22. Dent, M.P., 2007. Strengths and limitations of using repeat-dose toxicity studies to predict effects on fertility. Regul. Toxicol. Pharmacol., 48: 241-258. DOI: 10.1016/j.yrtph.2007.04.001

23. Husain, A., W. Sawaya, A. Al-Omair, S. Al-Zenki, H. Al-Amiri, N. Ahmed and M. Al-Sinan, 2006. Estimates of dietary exposure of children to artificial food colours in Kuwait. Food Addit. Contaminants, 23: 245-251. DOI: $10.1080 / 02652030500429125$

24. Chen, J., 2004. Challenges to developing countries after joining WTO: Risk assessment of chemicals in food. Toxicology, 198: 3-7. DOI: 10.1016/j.tox.2004.01.013 